\title{
Protecting traditional knowledge and expressions of culture in the Pacific
}

\author{
Michael Blakeney \\ Professor, University of West Australia
}

\section{INTRODUCTION}

The Pacific region has been a global pioneer of initiatives for the protection of traditional knowledge (TK) and expressions of culture (EC). The first regional initiative for the protection of TK and EC was the Regional Consultation on Indigenous Peoples' Knowledge and Intellectual Property Rights, held in April 1995, which issued the Suva Declaration $1995 .^{1}$ The declarants committed themselves to raising public awareness of the dangers of expropriation of indigenous knowledge and resources; the encouragement of chiefs, elders and community leaders to play a leadership role in the protection of indigenous peoples' knowledge and resources; and to incorporate the concerns of indigenous peoples to protect their knowledge and resources in legislation by including 'Prior Informed Consent or No Informed Consent' (PICNIC) procedures and exclude the patenting of life forms.

The Suva Declaration was one of a number of indigenous persons' declarations that had followed the Rio Earth Summit in $1992 .^{2}$ This activism in part stimulated the convening of the UNESCO/WIPO World Forum on the Protection of Folklore in Phuket in April 1997. There were calls at this forum for the establishment of an international regime to protect TK and EC. WIPO's response was the organization of expert missions to investigate the situation around the world.

Concerned about the apparently slow progress being made in the formulation of this international regime, the Pacific Islands Forum Trade Ministers Meeting in 1999 authorized the Secretariat of the Pacific Community (SPC) to address this issue. In 2002, the Model Law on Traditional Knowledge and Expressions of Culture was completed and was subsequently endorsed by the SPC Ministers for Culture for adoption by member countries, followed by Forum Trade Ministers in 2003. SPC members, in addition to the Pacific Island States, included Australia, New Zealand and the USA. These countries urged SPC members to await the results of the international negotiations being conducted at the World Intellectual Property Organization (WIPO), which appeared promising given the establishment in 2001 of establishment of the Intergovernmental Committee on Intellectual Property and Genetic Resources, Traditional Knowledge and Folklore (IGC).

As it has turned out, the work of the IGC has been very slow. During the first ten years of its existence the IGC has concentrated on the formulation of 'objectives' and 'principles' which should animate the protection of traditional cultural expressions

1. <http://www.idrc.ca/CCAA/ev-30152-201-1-DO_TOPIC.html>.

2. Eg the Mataatua Declaration (1993), the Kari-Oca Declaration (1992), Julayabinul Statement (1993). 
(TCEs) and TK. ${ }^{3}$ Concern has been expressed about the apparently slow pace in formulating an international instrument dealing with TCEs and TK. The African group of countries at WIPO were in the forefront of agitation there to accelerate international negotiations, but a true reflection of their appreciation of the realistic likelihood of action was the promulgation by a diplomatic conference on 9-10 August in Swakopmund, Namibia, organized by the African Regional Intellectual Property Organization (ARIPO), of a Protocol on the Protection of Traditional Knowledge and Expressions of Folklore. The Protocol is meant to "protect creations derived from the exploitation of traditional knowledge in ARIPO member states against misappropriation and illicit use through bio-piracy'. The protocol is also intended to prevent the 'grant of patents in respect of inventions based on pirated traditional knowledge ... and to promote wider commercial use and recognition of that knowledge by the holders, while ensuring that collective custodianship and ownership are not undermined by the introduction of new regimes of private intellectual property rights.'

A brief wave of enthusiasm on the international front was generated in October 2010, when the 17th session of the IGC, held on 6-10 December 2010, was identified as the occasion for the first text-based discussion of the establishment of an international TK and EC regime. The results of this session were not so exciting. ${ }^{4}$ An 'informal drafting group' was set up to provide a text on Traditional Cultural Expressions for the next meeting of the IGC, 9-13 May 2011. Further proposals for the protection of TK were made by a number of countries, to be considered by an Intersessional working group to meet on 21-25 February 2011. A third Intersessional Working Group, to meet on 28 February to 4 March 2011, will receive any further documents, which will be submitted on the subject of genetic resources.

\section{REGIONAL INITIATIVES}

The slowness of the developments at WIPO, as in Africa, has reactivated Pacific considerations for a regional solution. In March 2007, at a high-level meeting of the executives of the Pacific Islands Forum Secretariat (PIFS), and the SPC, it was decided that lead agency responsibility relating to the Model Law would move from the SPC to the PIFS. As a first step the PIFS convened a Workshop in June 2007 to determine member countries' technical assistance needs with regard to progressing the Model Law's implementation at the national level. The conclusions and recommendations of that Workshop were subsequently endorsed by Forum Trade Ministers in August 2007. A Traditional Knowledge Implementation Action Plan (hereafter 'the Action Plan') was formulated as a response to member countries' requests for technical assistance as conveyed to the PIFS at the Workshop.

The decision was also taken for the Pacific Island states to avail themselves of technical assistance which was being made available by the EU as part of the Partnership Agreement between the members of the African, Caribbean and Pacific (ACP) Group of States and the European Union (EU), signed 23 June 2000 ('Cotonou

3. The most recent contribution in this regard is a document of 7 June 2010 on the 'Protection of Traditional Cultural Expressions/ Cultural expressions of Folklore: Revised Objectives and Principles', which was prepared for the 17th meeting of the IGC in December 2010, WIPO/GRTKF/IC/17/4Prov.

4. See Decisions of the Seventeenth Session of the IGC, 10 December 2010 at $<$ http://www.wipo.int/meetings/en/details.jsp?meeting_id=20207>. 
Agreement') and concluded for a twenty-year period from March 2000 to February 2020. Two EU projects were initiated under this Agreement. The first, entitled 'Technical Assistance to the Pacific Regional Action Plan for Traditional Knowledge Development' ${ }^{5}$ has as its specific objective the provision of technical assistance for the establishment of national systems of protection for TK in six of the member states of the Pacific Islands Forum, namely Cook Islands, Fiji, Kiribati, Palau, Papua New Guinea and Vanuatu. A second project provided technical assistance to study the 'Feasibility of a Reciprocal Recognition and Enforcement Mechanism' for TK/EC between Fiji, PNG, Solomon Islands, the so-called Melanesian Spearhead Group (MSG) countries. ${ }^{6}$

The Terms of Reference for this latter project recognized that a regional approach would operate as a parallel, viable and faster alternative to the international developments. It was pointed out that any future collective arrangement would not preclude other countries from the wider Pacific region from participating in the system. These developments would instruct and inform global treaty-making processes currently taking place in institutions such as WIPO and possibly lead to engagement with other like-minded regions given the slow impetus to conclude a global regime for TK at WIPO, the World Trade Organization (WTO) and the Convention on Biological Diversity (CBD).

Both projects have been productive. National mapping of TK and EC has been conducted in the target states and draft intellectual property (IP) laws and policies have been formulated for Fiji, PNG and the Solomon Islands and a collaboration treaty has been drafted for the MSG states. The Treaty is to be submitted to the MSG Council of Arts and Culture for its consideration in January 2011 as the first step in the national ratification process.

\section{THE MSG REGIONAL COLLABORATION TREATY}

The Treaty imports elements of the Pacific Model Law for the Protection of Traditional Knowledge and Expressions of Culture, as well as the access and benefitsharing provisions of the Convention on Biological Diversity, which is reflected in the latter Model Law, but which is updated by the Bonn guidelines on access to genetic resources and fair and equitable sharing of benefits arising out of their utilization. Although designed for the MSG Members (Fiji, Papua New Guinea, Solomon Islands and Vanuatu), the Treaty can be extended to other States. The language of the Treaty took into particular account the documents which were prepared for the 17th session of the IGC. The Treaty was also designed to take into account the language of the Swakopmund Protocol. Finally, the language of the Treaty takes into account the various national approaches to the protection of TK and EC in MSG Members and at the same time seeks to function as a norm-creation agency in those countries.

\section{Preamble}

The preambular clauses locate the protection of TK and EC within Melanesian

5. $\quad$ Project No 9 ACP RPR.007.

6. Technical Assistance to Study the Feasibility of a Reciprocal Recognition and Enforcement Mechanism for TK between Fiji, Papua New Guinea, Solomon Islands and Vanuatu', TradeCom Facility Program, AOR.162-P177. 
cultures. They recognize the intrinsic value of Melanesian TK and EC, including their social, cultural, spiritual, economic, intellectual, scientific, ecological, agricultural, medical, technological, commercial and educational value and the need to respect traditional knowledge and expressions of culture, as well as the dignity, cultural integrity and intellectual and spiritual values of traditional, indigenous and local communities; to recognize and reward the contributions made by such communities to the conservation of the environment, to food security and sustainable agriculture, to the improvement in the health of populations, to the progress of science and technology, to the preservation and safeguarding of cultural heritage, to the development of artistic skills, and to enhancing a diversity of cultural contents and artistic expression.

Consonant with best international practice it is recognized that protection must reflect the need to maintain an equitable balance between the rights and interests of those who develop, preserve and maintain TK and EC and those who use and benefit from them. The primary beneficiaries of the protection envisaged by the Treaty are the owners and holders of TK and EC, although it is also recognized that society at large will benefit from the promotion of innovation, creativity and the transfer of technology.

Other objectives reflected in the Preamble are: the desire to conserve TK and EC from disappearance, erosion, misuse, unlawful exploitation and misappropriation, particularly the desire to preclude the granting and exercising of improper IP rights in TK and EC and in associated genetic resources and derivatives; and it reflects the collaboration and cooperation objectives of the Treaty in the recognition, protection, preservation, promotion and safeguarding of TK and EC.

\section{Article 1 Objectives}

Article 1 identifies four objectives for the Treaty:

(i) strengthening the cooperation and collaboration of MSG Members in the field of TK and EC with a view to promote sustainable development and contribute to the improvement of livelihoods in the MSG and the smooth and gradual integration into the world economy.

(ii) exploring the setting up of appropriate intra-MSG cooperation and collaboration arrangements in the field of TK and EC comprising a mutual recognition and enforcement regime founded on uniform national legal systems of protection.

(iii) promoting cooperation in the field among government agencies as well as among the private sector.

(iv) consultations on the development of MSG Members' TK and EC with a view to creating standards and practices which are consistent with international standards.

\section{Article 2 Principles}

Article 2 reflects these objectives in the principles which will apply to the interpretation of the Treaty. One area where the Treaty diverges from the developing international approach is that TK and EC are to be interpreted in a holistic sense, rather than in the approach which is being taken by the WIPO IGC, which conceives of $\mathrm{TK}$ as an industrial property matter and $\mathrm{EC}$ as a matter for copyright-related law. Also rejected is the WIPO IGC use of the expression 'Folklore', as this does not take into account the dynamic and evolving nature of TK and $\mathrm{EC}$ as frameworks of ongoing innovation. 


\section{Article 3 Definitions}

Article 3 incorporates a number of the definitions of the Pacific Model Law, and updates these where appropriate from the subsequent WIPO discussions. Article 3.2 provides that the specific choice of terms to denote the protected subject matter falling under TK and EC may be determined at the national level of a signatory.

\section{Article 4 National Competent Authority}

The Pacific Regional Action Plan (PRAP) for Traditional Knowledge (TK) Development envisages that States will designate or establish a national competent authority with responsibility for TK and EC and this is envisaged in Article 4 of the Treaty.

\section{Article 5 Protection of traditional knowledge and expressions of culture}

Article 4 defines the quality of the TK and EC which are: (i) generated, preserved and transmitted in a traditional and intergenerational context; (ii) distinctively associated with a traditional, indigenous or local community; and (iii) integral to the cultural identity of a traditional, indigenous or local community that is recognized as holding the knowledge through a form of collective and cultural ownership or responsibility. Such a relationship may be established formally or informally by customary practices, laws or norms.

\section{Article 6 Formalities relating to protection of traditional knowledge and expressions of culture}

Article 6 notes that the protection of TK and EC shall not be subject to any formality, but in the interests of transparency, evidence and their preservation, the relevant national competent authorities and the MSG Secretariat may maintain registers or other records of the TK and EC. Article 6.3 provides that the registers shall not compromise the status of hitherto undisclosed TK and EC. In furtherance of the collaboration and cooperation objectives of the Treaty, Article 6.4 provides that where two or more communities in the same or different countries share the same TK and $\mathrm{EC}$, the relevant national competent authority of the signatory and the MSG Secretariat shall register the owners and holders of the traditional knowledge and expressions of culture and maintain relevant records.

\section{Article 7 Beneficiaries of protection of traditional knowledge and expressions of culture}

Article 7 identifies as the beneficiaries of TK and EC protection their holders and owners, namely the traditional and indigenous communities, and recognised individuals within such communities, who create, preserve and transmit knowledge in a traditional and intergenerational context in accordance with the provisions of Article 5.

\section{Article 8 Rights conferred on holders of traditional knowledge and expressions of culture}

Article 8 confers upon the owners and holders of rights referred to in Article 5 the 
exclusive right to authorize the exploitation of their TK and EC and the right to prevent anyone from exploiting them without their free, prior informed and full consent. This imports the access principle from the CBD. The term exploitation in relation to TK envisages its embodiment in a product or making use of it in a process. This reflects the approach taken in the Swakopmund Protocol and includes: (i) manufacturing, importing, exporting, offering for sale, resale, selling or using the product; (ii) being in possession of the product for the purposes of offering it for sale, resale, selling it or using it; (iii) making use of the process beyond the traditional context.

'Exploitation' with reference to EC is defined along the lines of the Pacific Model Law for the Protection of Traditional Knowledge and Expressions of Culture in a copyright sense to include: (i) reproduction; (ii) publication; (iii) performance or display in public; (iv) broadcasting to the public by radio, television, satellite, cable or any other means of communication; (v) translation, adaptation, arrangement, transformation or modification; (vi) fixation through any process such as making a photograph, film or sound recording; (vii) making available online or electronically transmitting to the public (whether over a path or a combination of paths, or both); (viii) creation of derivative works; (ix) making, using offering for sale or resale, selling, importing or exporting expressions of culture or products derived therefrom; and (x) using in any other material form, if such use is a non-customary use (whether or not of a commercial nature).

Adopting the approach taken in the Pacific Model Law, excluded from proscription under the Treaty is the exploitation of TK or EC for any of the following: (i) face-toface teaching; (ii) criticism or review; (iii) reporting news or current events; (iv) judicial proceedings; (v) incidental use.

Article 8.6 provides that, in addition to all other rights, remedies and action available to them, the owners and holders of TK and EC shall have the right to institute legal proceedings against any person who carries out any of the acts of exploitation without the permission of the owners and holders.

\section{Article 9 Assignment and user agreements}

In furtherance of the objective of the appropriate commercial exploitation of TK and EC, Article 9 envisages that their holders and owners shall have the right to conclude user agreements. Article 9.2 provides guidance to the holders and owners by requiring that commercial user agreements must: (i) contain a benefit-sharing arrangement providing for equitable monetary or non-monetary compensation to the traditional owners; and (ii) provide for identification of the TK or EC on which the derivative work is based in an appropriate manner in connection with the exploitation of the derivative work by mentioning the traditional owners and/or the geographical place from which it originated; and (iii) provide that the TK or EC in the derived work will not be subject to derogatory treatment.

Article 9.3 provides that all access, authorizations, assignments or user agreements granted in respect of protected TK or EC shall be granted in writing, otherwise they shall be of no force or effect and that a document drawn up for the purpose of Article 9.3 shall be approved by the national competent authority, failing which the document shall be void.

\section{Article 10 Equitable benefit-sharing}

Article 10 imports the benefit-sharing principles from the Convention on Biological 
Diversity and the Bonn Protocol; it presupposes that the sharing of benefits in the first instance will be determined by mutual understanding between the signatories to a user agreement and that in the absence of such agreement the national competent authority shall mediate between the concerned parties with a view to arriving at an agreement on the fair and equitable sharing of benefits.

The right to equitable remuneration might extend to non-monetary benefits, depending on the needs and preferences expressed by the traditional, indigenous or local communities themselves.

\section{Article 11 Recognition of owners and holders of traditional knowledge and expressions of culture}

The moral right of the acknowledgement of paternity is provided by Article 11 which requires any person using TK or EC to acknowledge the owners and holders, indicate the source and, where possible, the origin, and use of such TK and EC in a manner that respects the cultural values of its owners and holders.

\section{Article 12 Exceptions and limitations applicable to the protection, preservation, promotion and safeguarding of traditional knowledge and expressions of culture}

Article 12 addresses the concerns which have been expressed by the holders and owners in international fora that the exploitation of TK and EC under user agreements might compromise the use by those holders and owners. Thus the article provides that the protection of TK and EC under the Treaty shall not be prejudicial to the continued availability of TK and EC for the practise, exchange, use and transmission of the knowledge and expressions of culture by its owners and holders.

\section{Article 13 Duration of protection of traditional knowledge and expressions of culture}

Article 13 provides that the TK and EC shall be protected for so long as they fulfil the protection criteria referred to under Article 5.

\section{Article 14 Administration and enforcement of protection of traditional knowledge and expressions of culture}

To ensure the effectiveness of the protection of TK and EC, Article 14 envisages that the national competent authority and MSG Secretariat acting on behalf of the Signatories to the Treaty shall be entrusted with the tasks of awareness-raising, education, guidance, monitoring, registration, dispute resolution, enforcement and other activities related to the protection of TK and EC. National competent authorities shall be entrusted, in particular, with the task of advising and assisting owners and holders of TK and EC in defending their rights and instituting civil and criminal proceedings, where appropriate and when requested by them.

Where two or more communities in different countries share the same TK or EC, Article 14.3 provides that the MSG Secretariat shall be responsible for raising awareness, education, guidance, monitoring, dispute resolution and other activities relating to the protection, preservation, safeguarding and promotion of TK and EC of those communities. 


\section{Article 15 Scope of cooperation and collaboration}

At the core of the Treaty is the definition of the cooperative and collaborative activities which Signatories will undertake in relation to TK and EC. Article 15.2 lists the types of cooperative and collaborative activities which may be undertaken. The list includes:

(i) Activities to enhance the protection and enforcement TK and EC, including: a. Crossborder measures cooperation; and b. Networking of judicial authorities and enforcement agencies.

(ii) Activities to strengthen the administration of TK and EC such as: a. automation to improve the administration of TK and EC; and b. the creation of databases on TK and EC.

(iii) Activities to strengthen legislation on TK and EC such as: activities related to the implementation of the international intellectual property conventions, the WTO TRIPS Agreement and conventions dealing with TK and EC.

(iv) Activities to promote human resource development such as: a. Networking of TK and EC training facilities or centres of excellence and to explore the possibility of establishing a regional training institute or other appropriate structures; and b. Exchange of personnel and experts.

(v) Activities to promote public awareness of TK and EC.

(vi) Activities to promote private sector cooperation on TK and EC, such as to explore the possibility of providing alternative dispute resolution mechanisms for the resolution of TK and EC disputes.

(vii) Information exchange on TK and EC issues.

(viii) Sharing of TK and EC for the public interest.

(ix) Other cooperative and collaborative activities as determined by the signatories to the Treaty.

\section{Article 16 Access to traditional knowledge associated with genetic resources}

Authorization under this Treaty to access protected traditional knowledge associated with genetic resources shall not imply authorization to access the genetic resources derived from the traditional knowledge.

\section{Article 17 Sanctions, remedies and enforcement}

In relation to enforcement, Article 17 requires that the Treaty signatories shall ensure that accessible and appropriate enforcement and dispute resolution mechanisms, sanctions and remedies are available where there is a breach of the provisions relating to the TK and EC. The national competent authority shall be entrusted with the task of advising and assisting owners and holders of protected TK and EC in protecting and enforcing their rights and instituting civil and criminal proceedings, where appropriate and when requested by the owners and holders concerned.

\section{Article 18 Regional protection}

Reciprocal protection is provided for owners and holders of the TK and EC of MSG members to the same level as owners and holders of TK and EC who are nationals of the country of protection, taking into account as far as possible the customary laws and norms applicable to TK and EC. This provision follows the design of reciprocal protection provided for in the Pacific Model Law and the various WIPO models. 
The possibility of the extension of reciprocal protection beyond the MSG is provided in Article 18.2, which requires that measures should be established by the national competent authority and MSG Secretariat to facilitate as far as possible such protection for the benefit of the holders of traditional knowledge and expressions of culture from non-MSG Members.

In cases of concurrent claims from communities of different countries with regard to TK and EC, the MSG may be entrusted with the task of settlement making use of customary law, local information sources, alternative dispute resolution mechanisms, and any other practical mechanism of this kind, which might prove necessary.

Finally, Article 18.4 provides that the judgments of courts of competent authority of an MSG Member shall be enforceable in all signatory countries.

\section{Article 19 Guidelines}

Article 19 permits the MSG Secretariat to make and amend guidelines for the implementation of the Treaty. Such guidelines and may:

(i) stipulate any administrative requirements, or any necessary details for the implementation of the provisions of the Treaty;

(ii) prescribe the procedure for applications of authorization to exploit TK and EC;

(iii) prescribe fees to be charged by the MSG Secretariat and the details of the distribution of fees among Signatories; and

(iv) provide forms to be used for matters requiring documentations under the Treaty.

\section{Article 20 Review of cooperative activities}

Article 20 provides that an MSG mechanism shall be established, comprising representatives from Members, to review the cooperative and collaborative activities under the Treaty. It shall meet on a regular basis to review the progress of these activities and any arrangement arising therefrom and to submit its findings and recommendations to the MSG Council of Arts and Culture, MSG Ministers of Arts and Culture and the constituent bodies of the MSG. The MSG Secretariat shall give necessary administrative support to the mechanism. Any differences between the MSG Members concerning the interpretation or application of this Treaty shall, as far as possible, be settled amicably between the Signatories.

Article 23 provides that the Treaty shall come into force three months after two States have deposited their instruments of ratification.

\section{TK/ECS AND GEOGRAPHICAL INDICATIONS}

A matter which the EU is interested in exploring in future projects with Pacific Island collaborators is the function which geographical indications (GIs) protection might play in the protection of TK and ECs, as well as in the development of the agriculturebased and handicraft industries of those countries. In its document describing the objectives and principles of TK protection, ${ }^{7}$ WIPO includes within the definition of TK any traditional knowledge associated with cultural expressions and genetic resources. ${ }^{8}$ In its equivalent document defining traditional cultural expressions

7. WIPO/GRTKF/IC/17/5.

8. Ibid, at para 3.2. 
(TCEs), ${ }^{9}$ it includes 'tangible expressions, such as productions of art, in particular, drawings, designs, paintings (including body-painting), wooden carvings, sculptures, mouldings, pottery, terracotta, mosaic, woodwork, metalware, jewellery, baskets, food and drink, needlework, textiles, glassware, carpets, costumes, works of mas, toys, gifts; and handicrafts; musical instruments; stonework, metalwork, spinning and architectural and/or funeral forms'.${ }^{10}$ Probably, the best-known agricultural product of the region is Kava. ${ }^{11}$

Within the Pacific Islands, there are a number of cultural artefacts, as well as agricultural products which could be protected both as TK/EC, as well as GIs. These would include the characteristic woven fabrics of the region, basketry, carvings, and even tattoos.

Obviously, the most focused protection for TK/EC would be through the international adoption of a mandatory sui generis system; however, in the absence of this, other categories of intellectual property protection have to be deployed. While most of the discussion to date has focused upon the role which patent and plant variety protection laws might play in the protection of TK, the objectives of GIs protection share a number of policy objectives with TK protection. ${ }^{12}$ Both TK and GIs protection systems seek to preserve communal rights. GIs are a collective right owned by all producers in a geographical region who observe the specified codes for production in that region. GIs have been described as a means of 'enabling people to translate their long-standing, collective, and patrimonial knowledge into livelihood and income', ${ }^{13}$ which has been identified as one of the core IP objectives of TK protection. GIs can be held in perpetuity, for as long as a community maintains the practices which guarantee the distinctive quality of a local product. This overcomes the limited terms of protection conferred by other forms of IP protection. On the other hand it should be noted that the proponents of TK protection emphasize its dynamism and capacity for development, which is not necessarily a characteristic of TK.

At all times it should be noted that GIs laws protect only the designations associated with products. Indeed, IP laws seldom protect knowledge as such. The exceptions to this are trade secrets law and patent law. However, empowering a local community or individual holder of TK with the possibility of excluding third parties from the unauthorized use of designations of its TK would better balance the sharing of benefits from the utilization of that TK. Finally, the extension of the scope of registered GIs protection under TRIPS would also provide an example for developing countries of the practical utility of an international IP regime and a justification for the implementation of the TRIPS Agreement.

\section{WIPO/GRTKF/IC/17/4.}

10. Ibid, para 1.1(d).

11. See DR Downes and SA Laird, Innovative Mechanisms for Sharing Benefits of Biodiversity and Related Knowledge Case Studies on Geographical Indications and Trademarks, UNCTAD Biotrade Initiative, 1999, Geneva <http://www.ciel.org/Publications/ InnovativeMechanisms.pdf>.

12. See M Blakeney, 'Protection of Traditional Knowledge by Geographical Indications' (2009) 3 Int J Intellectual Property Management 357.

13. L Bérard and P Marchenay, 'Tradition, Regulation and Intellectual Property: Local Agricultural Products and Foodstuffs in France', in SB Brush and D Stabinsky (eds), Valuing Local Knowledge: Indigenous Peoples and Intellectual Property Rights (Island Press, Covelo, CA 1999) 230 at 240. 